\title{
Exploring a national book-gifting scheme: Parents' and children's reactions
}

\author{
David Wray and Jane Medwell
}

Wray, D. \& Medwell, J. (2015) Exploring a national book-gifting scheme: parents' and children's reactions. Education 3-13. Vol. 43 (2), pp 209-222. http://dx.doi.org/10.1080/03004279.2013.800577

\begin{abstract}
Several early learning programmes have targeted children's reading, particularly their relationships with books. One, Bookstart, provided free books to babies attending their 8month health check at local clinics. Study of this programme suggested that it led to an improvement in language performance upon school entry. Booktime continues from Bookstart and involves the donation of a book pack to 5 year old children in their first school term. This paper reports an evaluation of the impact of Booktime on the views about, and enjoyment of, reading, of participating children and on the views of parents/carers about helping their children with reading.
\end{abstract}

\section{Keywords}

Reading, intervention, books, early childhood, parents

\section{Biographical notes}

David Wray is Professor of Literacy Education at the University of Warwick Jane Medwell is Associate Professor in Education at the University of Nottingham 


\section{Exploring a national book-gifting scheme: Parents' and children's reactions}

\section{Background}

Several early learning programmes have been premised on the idea that interventions targeted at children of a very young age can have a lasting impact on their social and cognitive development (Karoly et al, 2005). Research has generally offered positive support for the long-term effects of pre-school projects such as Head Start (Puma et al, 2010) and the High/Scope Perry Preschool Study (Schweinhart et al, 2005). Longitudinal studies of these programmes have shown that participants have consistently shown improved language and literacy performance upon school entry and lasting cognitive and behavioural benefits through childhood into adulthood. For example, by tracking the progress of children from the age of 3 to age 41, the High/Scope Perry Preschool Study demonstrated lasting effects on participant's later educational achievement, economic success, and avoidance of criminal activity (Schweinhart, 2003).

Studies of the relationship between children's attributes at school-entry, in terms of their academic, attention, and socio-emotional skills, and their later school achievement have consistently pointed to the importance of early language and reading as a preparation for, and a precursor of, school success. The meta-analysis reported by Duncan et al (2007), for example, concluded that the strongest predictors of later achievement were school-entry mathematics, reading, and attention skills, in that order of significance. It is unsurprising, therefore, that a major focus on many early intervention programmes has been the development of young children's reading. The ability to read does, of course, make many

high cognitive demands and there has been considerable debate about the most suitable age at which to begin formal instruction in this skill. With children aged 0 to 4 years, the emphasis has tended to be on developing their attitudes towards reading rather than their skills in performing it (Wade \& Moore, 2000; Hines \& Brooks, 2005; Mol et al, 2009). Programmes designed to develop children's relationships with reading, and with books, have proved quite popular.

Perhaps the best known of such book-based interventions has been the Reach Out and Read programme, begun in the US in 1989 (see Needlman, et al., 1991 for the first reported study of this initiative). This programme is designed to promote early literacy and is based around 
the paediatric care clinics which children attend, with their parents, between the ages of 6 months to 5 years. At these clinics, the paediatricians (doctors or nurses) distribute new books to the children and advice to the parents about the importance of reading aloud. The central organisers of Reach Out and Read (http://www.reachoutandread.org) describe the main thrust of the programme as 'prescribing books' (Sanders et al, 2000). The impact of this intervention has been very strongly supported by empirical evidence regarding its effectiveness, mostly published in the medical, rather than educational literature. Studies (e.g. Weitzman et al, 2004; Needlman et al, 2005; Byington et al, 2008) have shown that parents whose children receive paediatric care at Reach Out and Read sites tend to read to their children more frequently, own more books, and are more likely to describe reading aloud as a favourite activity. Even more compellingly, several studies (e.g. Mendelson et al, 2001; Sharif et al, 2002) have found that children receiving care at Reach Out and Read sites demonstrate greater language abilities than their non- Reach Out and Read peers.

One comparable, UK-based programme, Bookstart, also focused its intervention on the provision of free books to parents whose babies were attending their 8-month health check at local health clinics. More recently, this has been supplemented by Bookstart+, in which another book is given to children at their two-year health check. Studies have yet to track the progress of Bookstart children beyond the primary years, but there does appear to be growing evidence of the positive effects of this intervention. O'Hare and Connolly (2010), for example, have reported strong evidence of a positive effect of Bookstart on parents' attitudes to reading and books and some evidence of an improvement in parental attitudes to their child reading. The longitudinal study reported by Wade and Moore (2000) and Moore and Wade (2003) has suggested that being involved in the Bookstart programme had led to an improvement of language and literacy performance upon school entry at the age of four. Tracking children's performance up to their Key Stage 1 assessment at age seven, Wade and Moore's research suggests that Bookstart children maintained this advantage throughout their first three years of primary education. Mean scores for a range of literacy and numeracy tests showed Bookstart children outperforming their non-Bookstart counterparts by between 1 and 5\% (Wade and Moore, 2000). In a similar, locally-based study, Hines and Brooks (2005) found that Bookstart children had acquired consistently higher levels of language and literacy development than non-Bookstart children. Bookstart children recorded 20\% superior scores in Listening and Speaking, 19\% for Reading and 12\% for Writing. Similarly positive outcomes were reported in a Nottinghamshire-based study (Bailey et al., 2000, 2002). 
Such positive impacts are, research suggests, the product of two distinct features of interventions such as Bookstart. Firstly, the programme is predicated upon the close relationship of parent and child in the home. Secondly, research has consistently demonstrated the benefits of parents and their children reading together at home. The emotional closeness that arises as books are enjoyed together appears to add an additional quality to the learning experience. Shared storybook reading between parent and child therefore produces a natural and productive learning experience for the child. A home environment in which parents actively introduce their children to books has been shown to nurture the type of literacy skills and understanding that lead to the later acquisition of literacy. Children become familiar with the page- structure of books, learn how to identify print and orient themselves to story structures (Baker et al, 1998; Senechal \& LeFevre, 2002; Snow \& Ninio, 1986). This kind of shared experience with a trusted parent is believed to further support the acquisition of literacy by encouraging interest and motivation towards books and reading. Studies suggest that it is the quality of the shared reading experience that determines its effectiveness in nurturing literacy skills. More crucial than whether the parents read to the child every day or less often, is the extent of the child's active participation in these situations (Crain-Threson \& Dale, 1992). According to Whitehurst and his colleagues (Whitehurst et al., 1988) active engagement of the child predicts his or her later language and literacy skills more strongly than any other parental variables related to book reading.

Among the many sources of evidence for the benefits of shared reading is Beal et al's (1994) study of the outcomes of different learning environments. This involved a longitudinal study of children who, during their toddler years, had been exposed to shared reading in the home, against a control group who had not. At the age of five, the children underwent a series of tests to measure their language and literacy skills. The tests included a narrative production task in which the child was asked to tell a story about a group of bears shown in three photographic slides that the evaluator could not see. The purpose of the task was to evaluate the child's ability to produce a narrative for someone not privy to the same visual information. In addition, the study assessed the child's print skills, such as recognition of print words, identification of alphabet letters, the comprehension of story and print concepts, as well as phonemic awareness and writing skills. 
The study found that the incidence of structured conversation in shared reading was correlated with the child's performance on the test of early print skills. In other words, the parent who made book reading a rich and cognitively challenging event was also helping his or her child to develop a familiarity with how books worked and what you needed to do to read one. Engaged shared reading was also shown to support the more sophisticated skills of story comprehension and story production.

Overall, research provides powerful evidence to suggest that the language interactions of young children with adults are important determinants of children's literacy development. Because literacy development is closely related to the development of language skills, challenging verbal interaction with adults can be a powerful promoter of early literacy for young children. The shared reading experience advocated by programmes such as Bookstart seems to speak to precisely this kind of practice.

\section{Moving on to older children}

The studies reviewed above have largely focused on pre-school interventions, and, in the case of Bookstart, very early indeed in children's lives. Other interventions have targeted older children, and there have also been tracking studies (e.g. Sylva et al, 2003) designed to explore school-based features associated with children's achievement. It is an intervention aimed at children beginning school which is the focus of the evaluation reported in the current paper. Booktime is a programme set up by education and publishing company Pearson, in association with independent charity Booktrust, to promote the pleasure of reading and encourage parents and carers to read aloud with their children. The programme was supported by the UK government, through the Department for Children, Schools and Families (DCFS), and involved the donation of a book pack to every reception aged child (children in their first terms in formal, maintained schools are referred to in the UK as 'reception' children). These packs were delivered to schools in partnership with local authorities and library services. The aim was to give children aged 4 to 5 the gift of an illustrated book shortly after they started school, to take home to share with family and friends. The books were to be handed out by teachers in a special book bag, along with a guidance booklet for parents and carers on shared reading with their children. In addition, participating schools and libraries in England were given a resource pack to facilitate the 
children's enjoyment of the book, containing items such as stickers, badges, and a poster as well as an activity and session ideas booklet.

\section{The evaluation}

An evaluation of the Booktime programme was commissioned with its aim being to evaluate the impact that the Booktime experience had on:

- the time children spent reading with their families;

- their views about, and enjoyment of, reading;

- the views of their parents/carers about helping their children with reading;

Evidence relating to these questions was collected via a sequence of interviews with twenty five parents/carers whose children had received Booktime book packs.

\section{The Use and Conduct of Interviews}

In this evaluation, interviews were used as a means of gathering qualitative data. In this case we were enquiring into the impressions of parents/carers whose children had received a Booktime book pack about the reactions of these children to the material they had received.

A general consensus in terms of research methodology is that interviews have a number of strengths as data-gathering tools.

- They are good for gauging attitudes.

- They allow probing and the posing of follow-up questions by the interviewer.

- They can provide more in-depth information than questionnaires.

- They are useful for exploration as well as confirmation.

These strengths mapped well onto our purposes for the use of interviews in this evaluation, where we were principally interested in exploring in some depth the attitudes of the participants. We need to recognise, however, that the use of interviews also carries with it some problematic issues in terms of the data gathered.

- Interviews can produce reactive effects: for example, interviewees may express attitudes which they feel the interviewer wishes to hear. 
- Interviewees may not remember important information and/or may have a distorted memory of significant events in the formation of their attitudes.

- The perceived anonymity of respondents is low and this may limit what they are prepared to say in an interview.

In our interviewing of the parents/carers in this evaluation, we tried to take account of the above potential problems by the following strategies.

- All interviews were carried out in participants' homes and on their terms. Venue was seen as a particularly important feature in reducing the constraints upon the views participants felt able to express. Participants also had complete freedom over the duration of each interview, and it was always their decision when to terminate the event. Interviews thus ranged from 45 minutes to one and a half hours, and the amount of 'social talk' each contained was determined by the individual participant.

- Interviews did not follow a set agenda. We did approach them with a number of issues we wished to discuss with participants (see below) and we began each interview by explaining to the parent/carer what these issues were. From that point on, however, there was considerable freedom given to participants in how they responded to the starting statements we used (or indeed, whether they responded). Each interview was therefore very open-ended and our concern was always to follow the line of thinking of each participant rather than impose our agenda upon them.

- All participants were assured at the beginning of each interview (and beforehand in our initial contact with them to arrange these interviews) of absolute confidentiality in the outcomes of what they told us. None of them would be identified in any report of the outcomes of the interviews. For a small number of them we were specifically asked whether personnel at their child's school would know what they said in the interview and, again, we assured them that, although school personnel did know they were being interviewed (these parents/carers had been suggested by the head teachers of their children's primary schools) their responses in the interview would be completely anonymous.

Interviews were, therefore, conducted more in the form of conversations rather than questionanswer sessions. This had the advantage of allowing a good deal more probing and follow-up of responses that would otherwise have been the case. 


\section{Participants}

The interview participants were 25 parents/carers whose children had received book packs as part of the Booktime programme. Their children were members of reception classes in primary schools who were part of our University's teacher training partnership.

The participants were all volunteers. We were initially given a list of suggested names by the head teachers of nine local primary schools selected, more or less, randomly from those schools within the partnership. Head teachers were asked only to suggest the names of 3 to 4 parents they felt might be available for a meeting with us in the early evening. The original list of suggested parents/carers contained 34 names. We approached these in random order to ask if they would be willing to participate in the interviews until we had the required 25 participants. In fact, only one parent declined (she did not give a reason). Interviews of these parents/carers were carried out during a six week period.

Participants were from a range of social backgrounds. We did not ask them for details of their backgrounds (this not being one of our research questions) and our judgement about the range they represented is made largely on the basis on geographical location, which may, of course, be misleading as an accurate guide. What we can say is that of the 25,6 belonged to minority ethnic groups and 4 showed evidence of using English as an additional language (two of whom told us they had arrived relatively recently in this country from Poland). 24 of the 25 were female and the solitary male was, he informed us at the interview, a single parent.

\section{Interview contents}

The interviews were conducted according to the following 'rules':

- Each interview was conducted in the participant's home and began with social 'chat' as we got to know each other. In every case, tea or coffee was offered to us at the beginning of the interview and the making and drinking of this was used as an 'icebreaking' opportunity. 
- Each interview proper was begun with a statement that we were enquiring into the Booktime programme and how it was working, and we were interested in parents' views about this.

- We introduced ourselves as being from the University and being outside the Booktime programme, having no direct involvement with it other than having been asked to evaluate it.

- In each interview, we had a list of topics we wished to explore but these were often not initially expressed as questions. We explained to the participants that our main role was to listen to what they had to say. We did use questions to follow up the introduction of particular topics as we tried to probe initial responses. There were many occasions, however, on which this was unnecessary as participants tended to be fairly talkative without our prompting. In only one of the 25 interviews was the conversation at all 'difficult', as the parent began to explain a problem she was currently having with her child's teacher, who was not, apparently, giving this child sufficient individual attention in reading. We allowed this conversation to proceed for a while before bringing the parent back to Booktime by explaining that this was actually not connected with the school's provision.

- All participants were asked if they would agree to the digital recording of the interviews. None of them had any objection to this. Interviews were recorded and subsequently transcribed for analysis.

Our initial list of topics was as follows:

- The Booktime bag and its contents (introduced in words such as, "We would be really interested in what you thought about the book and the bag your child was given as part of Booktime.")

- Children's reactions to the bag and the book. ("I don't know what (name of child) thought about the book.")

- Ways in which the book has been used. ("There are lots of things you might have done with the book when (name of child) brought it home.")

- The impact of the Booktime pack on their children's reading. ("Would you say the Booktime book pack has helped (name of child) in beginning reading?") 
- The future and likely longer term impact of Booktime. (“So, do you think Booktime should carry on next year or should they do something different?" and "I wonder if (child's name) will have forgotten all about Booktime in a couple of years.")

During each interview, we were also able, briefly, to talk to the participating child, always in the presence of at least one of their parents/carers. The conversation proceeded in the following way:

- "Do you remember the Funnybones book you were given at school?"

- Some children needed the prompt of, "You remember, it came in that blue bag."

- For 22 out of the 25 this was sufficient and they produced the book itself (it sometimes took a bit of searching!).

- With the remaining 3, we showed them a copy of the book and they all then claimed to remember it.

- We then made a statement along the lines of, "I really liked the bit when ..". 20 of the 25 children then told us about bits that they liked without further prompting.

- With the remaining 5, we asked them directly to show us a bit they liked and they each did.

- If they showed interest in reading out loud to us from the book, we greeted that with enthusiasm but this was not something we directly asked them to do (in three cases the parent/carer volunteered the child for reading aloud and fortunately in each case this was not a problem for the child.)

Our over-riding principle was that our conversation with the child had to be fun and not construed as any kind of a test of their reading. We think that, in all cases except perhaps for one, we were successful in this. In one case, coincidentally the interview in which the parent had expressed concern about her daughter's school, there was clearly an element of 'showing off' the child's reading prowess to us. We simply listened and responded enthusiastically to this.

\section{Interview outcomes}

In the following sections, we will report the outcomes of the interview discussions about each of the topics. We will indicate in our reporting the extent to which certain views were 
expressed by participating parents/carers, and children. In general, we will not report views which were only expressed by one or two parents.

The Booktime bag and its contents

There was unanimous appreciation of the gift their children had received. Several parents/carers (16) made positive comments about the quality of the book.

That was a really good choice of book - Joanne really liked it.

What a nice book! We didn't get given books like that when I was at school.

4 parents/carers, interestingly enough the parents of boys, made comments about the nature of the book in which they indicated their children would have preferred a non-fiction book.

I think Jamie would have liked something about dinosaurs or cars. He likes fact books more than stories.

The story's quite good fun but I think he wanted more information in it.

3 parents/carers, while expressing gratitude for having received the book, had some doubts about its suitability.

I was a bit surprised it was about skeletons. Don't you think that's a bit scary?

Lianne liked the book but I thought it was a bit frightening for her. She does have nightmares sometimes and / don't want to make it worse.

Children's reactions to the bag and the book (reported by parents/carers)

20 of the parents/carers reported a very positive reaction to the Booktime book pack on the part of their children. 
Alexander already has the Funnybones book but he still loved being given the pack. He's given his old book to his little sister.

Emily brings other books home from school so we didn't know at first that this was special. She soon told us though!

For the 5 remaining parents/carers, the reactions were not negative but rather non- committal.

Well, he quite liked it. I still think he would have liked an information book better.

It was OK. He didn't want to read the book to me though. He was much more interested in watching the telly when he came home.

Inevitably, reactions to the bag were as positive as reactions to the book. 18 of the group said that their children had been very pleased with the bag.

She really loved that bag. She keeps her colouring pens in it now.

It was the bag as much as the book, you know. That's a clever idea!

In 22 of the 25 homes we visited we saw evidence that the bag was still a treasured item, and 8 children still kept their Funnybones book in the bag!

One parent reported explicitly what many of them hinted at:

I think having the book in the bag definitely makes the children want to read it more. They all love things like bags, don't they?

Children's reactions to the Booktime book pack (reported by children)

As we mentioned above, for 22 out of the 25 children that we talked to the question, "Do you remember the Funnybones book you were given at school?" and, sometimes, the prompt of, "You remember, it came in that blue bag" were sufficient to get them to remember and then produce the book itself. With the remaining 3, we showed them a copy of the book and they 
all then claimed to remember it. This suggests that the impact of the book and its bag had been very high on this particular group of children. There were, as far as we could tell, no negative reactions to the book at all among these children: indeed, big smiles were far more characteristic of their reactions.

When we then made a statement along the lines of, "I really liked the bit when ..." this led to 20 of the 25 children telling us about bits that they liked without any further prompting. With the remaining 5, we asked them directly to show us a bit they liked and they could each do that.

8 of the children (including 3 who were volunteered by their parents/carers) read aloud to us from the book, in each case with good expression and obvious understanding. 7 others did not read aloud (they were not directly asked to) but did point to illustrations in the book with obvious signs of enjoyment.

As mentioned above, 22 of these children could produce the bag in which they received the book, and 8 of them still kept the book in this bag. All of the others were using the bag to store other items including other books (6), toys (7) and a collection of small stones (1).

\section{Ways in which the book had been used}

A range of ways of using the book were reported. These are listed below:

- $\quad$ parent/carer reading the book to/with the child (reported by 21 parents);

- $\quad$ arent/carer and child talking about the pictures in the book (17);

- child drawing his/her own pictures of the book characters (11);

- child retelling story to the parent/carer (7);

- parent/carer asking child to read the book to her/him (6);

- $\quad$ arent/carer and child taking turns to read parts of the book (4);

- $\quad$ arent/carer talking about individual words in the story with child (4);

- child and parent/carer acting out parts of the story (3).

Given the age and reading experience level of these children, this is quite a positive finding in that it suggests that these parents and carers were generally not trying to force their children 
to read aloud but were allowing enjoyment of the shared reading experience to take precedence.

Nobody in the sample mentioned using the book to teach sounds and letters to their children, again an indication of the lack of pressure to learn that was characteristic here.

One parent did express this idea quite forcefully:

I think the teachers can teach her how to read. I'm much more interested in making sure she wants to.

The impact of the Booktime book pack on children's reading

This is probably the most important of the topics we explored during the interviews as it bears directly upon the fundamental question surrounding the Booktime programme - was it worth it? The evidence from these interviews suggests that the answer to this question should certainly be positive. We need, however, to bear in mind the nature of the evidence we are presenting here. This is not objective data in the sense of external assessments of the progress in reading made by the children involved. Given the young age of these children and the 'blunt instrument' nature of most assessments of reading progress, there was no conceivable way in which our evaluation could have gathered such objective data. The target children had been in school for 5 months or so. Their progress in actually reading would, within the span of our evaluation, have been fairly minimal anyway, and almost certainly not measurable in an objective sense.

The aim of Booktime was never expressed in terms of improvements in measurable reading ability in the children involved (although its aspirations would certainly include that). Instead, the focus was placed on the enjoyment of reading:

Booktime promotes the pleasure of books by encouraging families to have fun reading together. The programme supports, encourages and enables reading for pleasure at home at an important transition stage in a child's learning and development. (http://www.booktime.org.uk/about-us/) 
The focus of our interviews, therefore, was on this aim, although in all interviews we also asked parents and carers whether they thought that having received the Booktime book pack had impacted in any way on their children's reading ability. Their responses, although of course subjective rather than objective evidence, were almost unanimously positive.

This was one of the few parts of the interviews which we did initiate with a question: "Would you say the Booktime book pack has helped (name of child) in beginning reading?" 23 of the 25 parents gave the instant response to this question - "Yes". The first response of the remaining 2 parents was, "I'm not sure."

We probed these responses further, using open questions such as, "What makes you say that?" Parents gave a number of reasons for their views. These are summarised in table 1.

Table 1: Parent views on the impact of Booktime on their children

\begin{tabular}{|l|c|}
\hline Generalised statement made by parents & $\begin{array}{c}\text { No. ofparents making } \\
\text { such a statement }\end{array}$ \\
\hline My child asks me to read to him/her more often than before & 19 \\
\hline My child is a lot keener about books that he/she was & 18 \\
\hline My child talks about books more than before & 16 \\
\hline My child has brought books home from school to read & 15 \\
\hline My child has read aloud to me from Funnybones & 14 \\
\hline My child has asked for books as presents & 13 \\
\hline
\end{tabular}

N.B. Parents/carers often made more than one of these statements.

These responses suggest that the perceptions of these parents and carers were that the Booktime experience had definitely affected their children's attitudes towards, and expertise in, reading for the better.

The future and likely longer term impact of Booktime

Our conversations around this topic were intended to get the parents/carers' perspectives on two issues. The first was what they thought the future of Booktime might look like ("So, do 
you think Booktime should carry on next year or should they do something different?"), and the second was their views on any longer impact of Booktime on their own child ("I wonder if (child's name) will have forgotten all about Booktime in a couple of years.")

For 16 of the 25 parents, the question of the future of Booktime was relatively simple. They thought it should carry on because then their younger children would also have the experience of receiving a book pack.

His little sister is already asking when she's going to get her bag.

I hope it's still going when the twins go to school. But they'd better get one each or we'd never hear the last of it!

6 of this group also thought Booktime should continue because of its highlighting the enjoyment of books among all the other things children could do.

I'm sure kids don't read as much as they used to - they've all got their playstations these days. Giving them books like this might be the only way to get them going in their reading.

They get free toys from Macdonalds so I think they should get free books as well.

Of the remaining 9 parents/carers, 5 gave a mixture of reasons why the scheme should continue.

It's a lovely idea. It would be a shame to stop it now.

It definitely makes them like books more so I think they should carry it on, yes I do.

Only 4 of the parents/carers had negative views about the future of Booktime and even then, these were pretty mild.

It can't go on forever. Better to have a big splash and stop before it gets boring. 
When it came to the longer term impact on their own children, the majority of the parents/carers were fairly realistic. Only 3 expressed the view that the impact would be a very long term one.

Well, I think it's changed Charlotte. She feels differently about books now.

Others were more sanguine in their views.

Lots of things happen in kids' lives. I'm sure they forget most things even the good ones.

Perhaps the most considered reaction came from one parent whose son she reported as being 'over the moon' with the book.

Well, of course, Sam thinks it's brilliant now but he's bound to forget, isn't he? They always do. But you hope that some little bit of that good feeling might just stay around. I guess it's my job now, to keep him interested and keen. Booktime's a good start but we haven't got there yet.

These reactions suggest an enthusiastic, but honest, appraisal of the long term impact of the Booktime programme. Most of these parents/carers were not naive about the long term impact of a single event, however pleasurable that event was. They recognised, for most implicitly, that it would need sustained activity to make a significant change in long term behaviour.

\section{Summary of findings}

The key findings of this evaluation are presented below.

- There was an almost unanimous positive reaction to the Booktime pack (bag and book) among parents/carers and children. There is no doubting the delight with which these packs were generally received and many positive comments were made by the recipients. 
- Some of this positive reaction must, however, be attributed to the Booktime bag rather than the book it contained, although it is quite possible that children's attraction to the bag might well transfer to their feelings about the book inside!

- The book itself was valued highly by the vast majority of parents/carers and children.

- A small minority of parents/carers had some concerns about the appropriateness of the book, with some expressing worries about it being too scary, not the right genre, or too difficult.

- A variety of uses had been made of the book. These included reading it to children; talking about the pictures and/or the story; children reading or retelling the story to an adult; children acting out parts of the story.

- Parents/carers had not used the book for more deliberate teaching purposes, for example, teaching letters and sounds.

- There was strong support for the continuation of the Booktime scheme into future years.

\section{Discussion}

The question to which we would like to have been able to provide an answer, however tentative, was, quite simply, "Did Booktime make a difference to children's reading?" It should be noted, however, that the design of this evaluation of the project did not allow us to give a categoric answer to this question. To provide such an answer would have required a controlled experiment, with before and after measures.

Booktime was not, in fact, set up with the principal aim of affecting children's reading progress, nor was the evaluation intended to measure changes in this. The evidence we were able to collect was entirely self-report, from stakeholders after the main event of the intervention, the distribution of the book packs, had already happened. Therefore, we have no objective measures of the attitudinal changes towards books and reading made by the children involved in Booktime, but rather, subjective impressions of such changes from their parents/carers. Although by its nature such evidence is intrinsically weaker than objective measures would have been, its main strength, in the event, is that it is internally consistent. 
There was clear evidence that the parents/carers, and their children, were virtually unanimous in their conviction that the experience of Booktime had enhanced both the enjoyment of and the achievement in reading of the children involved. This outcome matches those found in other, equivalent studies. Enjoyment of books and motivation to engage with them has been found to have flowed from the Reach Out and Read initiative in the US (see Needlman et al, 2005 as just one piece of evidence for this).

This increased enthusiasm for books and reading was also associated with an increase (so parents told us) of book-sharing, along with its associated social interaction, between parents and children. Again, a similar finding emerged from the Reach Out and Read research (e.g. Weitzman et al, 2004). Other evidence (for a meta-analysis see Bus et al, 1995) has also suggested that storybook sharing between parents and children appears to be linked to enhanced reading achievement in these children. It is not, it has been argued, simply a matter of providing children with reading materials, but more crucial is the stimulation of joint interest in and enthusiasm for shared reading in both parents and children. As Bus et al (1995) put it:

"it seems reasonable to assume that interest in reading is as much a prerequisite as a consequence of book reading, and that the mere presence of models and materials such as books may not stimulate children's development as effectively as parental support during book reading activities". (p. 3)

The evidence suggests that it what Raikes et al (2006) refer to as 'concurrent reading' that is important and that regular experience of this links strongly with children's language development, and thence their reading development. A more recent meta-analysis (Mol et al, 2009) has confirmed that interactions between parents and children focused upon books and stories appear to be a key stimulus for children's vocabulary development and their knowledge of print and its conventions.

It seems, therefore, defensible for us to argue that a longer term outcome of experience with Booktime may well be enhanced reading achievement in the children involved. We have presented evidence that the children and the parents experiencing Booktime say that this experience has led them to read books together. The literature suggests that enhanced reading achievement is often an outcome of such interactive reading. 


\section{Conclusion}

Notwithstanding the caveats, which we have been at pains to point out in our paper, we would still argue that, from the evidence available to us, the children experiencing Booktime had been positively involved with books in a way that is likely to have a longer term impact upon their approaches to reading. They, and their parents, had developed an increased enthusiasm for books and reading. This enthusiasm had led to an increase in parent-child interactions focused on books, and such interactions, according to the literature, appear to be related to increased reading achievement in children.

Of course, a major weakness in the argument here is that our evaluation was, necessarily, concentrated upon one distinct time period, when the receipt of the Booktime book pack was relatively fresh in the minds of parents and children. A much stronger test will be to explore the longer term impact of the experience, particularly upon the participating children. Such longer term assessments of interventions with young children are comparatively rare in the educational research literature, although we began this paper by referring to, perhaps, the best known longitudinal study in the area, that of Schweinhart et al (2005). For interventions comparable to that evaluated here, the example of Moore \& Wade (2003) has been influential, although even in this case, the evidence stops when the children involved reached 7 years old. Research needs to be conceived over a longer time scale if a true costs-benefits analysis is to be achieved for projects such as Booktime. The project itself has become long term, having now begun its seventh year of operation. The children who took part in its first iteration, in 2006, are now into their secondary school years. It would be interesting, and important, to explore any continuing effects from their experiences with the first Booktime book, Lynley Dodd's Hairy Maclary’s Bone.

\section{References}

Bailey, M., Harrison, C. and Brooks, G. (2000) The Boots Books for Babies Project Evaluation. Nottingham: University of Nottingham, School of Education.

Bailey, M., Harrison, C. and Brooks, G. (2002) The Boots Books for Babies project: Impact on library registrations and book loans. Journal of Early Childhood Literacy, 2 (1), 45-63. 
Baker, L., Frenandez-Fein, S., Scher D. \& Williams, H (1998). 'Home experiences related to the development of word recognition' in Metsala, J. \& Ehri, L. (eds.) Word recognition in beginning literacy. Mahwah, NJ: Erlbaum.

Beals, D., DeTemple, J., \& Dickinson, D. (1994). 'Talking and Listening that supports Early Literacy Development of Children from Low-Income Families' in Dickinson, D. (ed.) Bridges to Literacy: Children, Families and Schools. Oxford: Blackwell.

Bus, A., Van IJzendoorn, M., \& Pellegrini, A. (1995). Joint book reading makes for success in learning to read. A meta-analysis on intergenerational transmission of literacy. Review of Educational Research, 65 (1), 1-21

Byington, C., Hobson, W., Olson, L., Torres-Nielsen, G., Winter, K., Ortiz, K. \& Buchi, K. (2008) 'The good habit of reading (El buen habito de la lectura): Parental reactions to an enhanced Reach Out and Read program in a clinic for the underserved.' Journal of Health Care for the Poor and Underserved. 19 (2), 363-368.

Crain-Threson, C. \& Dale, P. S. (1992). 'Do early talkers become early readers? Linguistic precocity, preschool language, and emergent literacy'. Developmental Psychology, 28 (3), 421-429.

Duncan, G., Dowsett, C., Claessens, A., Magnuson, K,. Huston, A., Klebanov, P., Pagani, L., Feinstein, L., Engel, M., Brooks-Gunn, J., Sexton, H., Duckworth, K. \& Japel, C. (2007) 'School Readiness and Later Achievement'. Developmental Psychology, 43 (6), 1428- 1446

Hines, M. and Brooks, G. (2005) Sheffield Babies Love Books: An Evaluation of the Sheffield Bookstart Project. Sheffield: University of Sheffield.

Karoly, L., Kilburn, M., \& Cannon, J. (2005). Early childhood interventions: Proven results, future promise (Rep. No. MG-341). Santa Monica, CA: RAND. (http://www.rand.org/pubs/monographs/2005/RAND_MG341.pdf)

Mendelsohn, A., Mogiler, L., Dreyer, B., Forman, J., Weinstein, S., Broderick, M., Cheng, K.J., Magloire, T., Moore, T. \& Napier, C. (2001) 'The impact of a clinic-based literacy 
intervention on language development in inner-city preschool children.' Pediatrics 107 (1), 130-134.

Mol, S., Bus, A., \& de Jong, M. (2009). 'Interactive book reading in early education: A tool to stimulate print knowledge as well as oral language'. Review of Educational Research, 79 (2), 979-1007.

Moore, M. and Wade, B. (2003) 'Bookstart: A Qualitative Evaluation'. Educational Review, $55(1), 3-13$

Needlman, R., Fried, L., Morley, D., Taylor, S. \& Zuckerman, B. (1991) 'Clinic-based intervention to promote literacy: a pilot study.' American Journal of Diseases of Children, 145 (8), 881-884.

Needlman, R., Toker, K., Dreyer, B., Klass, P. \& Mendelsohn, A. (2005) 'Effectiveness of a primary care intervention to support reading aloud: a multicenter evaluation.' Ambulatory Pediatrics 5 (4), 209-215.

O’Hare, L. \& Connolly P. (2010) A Randomised Controlled Trial Evaluation of Bookstart-/-; A Book Gifting Intervention for Two-Year-Old Children, Belfast: Centre for Effective Education, Queen's University Belfast.

Puma, M., Bell, S., Cook, R. \& Heid, C. (2010) Head Start Impact Study Final Report. Washington, DC: U.S. Department of Health and Human Services

Raikes, H, Pan, B., Luze, G, Tamis-LeMonda, C., Brooks-Gunn, J, Constantine, J, Tarullo, L., Raikes, H.A, \& Rodriguez, E. (2006) 'Mother-child book reading in low-income families: correlates and outcomes during the first three years of life'. ChiVd Development. 77(4): 92453.

Sanders, L., Gershon, T., Huffman, L. \& Mendoza F. (2000) 'Prescribing books for immigrant children.' Archives of Pediatrics and Adolescent Medicine. 154 (8), 771-777. 
Schweinhart, L. (2003) Benefits, Costs, and Explanation of the High/Scope Perry Preschool Program. Paper presented at the Meeting of the Society for Research in Child Development, Tampa, Florida. April 26, 2003.

Schweinhart, L., Montie, J., Xiang, Z., Barnett, W., Belfield, C. \& Nores, M. (2005) Lifetime effects: The HighScope Perry Preschool study through age 40. (Monographs of the HighScope Educational Research Foundation, 14). Ypsilanti, MI: HighScope Press.

Senechal, M. \& LeFevre, J. (2002) 'Parental involvement in the development of children's reading skills: A five-year longitudinal study.' ChiVd Development, 73 (2), 445- 460

Sharif, I., Rieber, S. \& Ozuah, P. (2002) 'Exposure to Reach Out and Read and vocabulary outcomes in inner city preschoolers.' Journal of the National Medical Association, 94 (3), 171-177.

Snow, C. \& Ninio, A. (1986) 'The contracts of literacy: What children learn from learning to read books' in Teale, W. \& Sulzby, E. (eds.) Emergent Literacy; Writing and reading, Norwood, NJ: Ablex.

Sylva, K., Melhuish, E., Sammons, P., Siraj-Blatchford, I., \&Taggart, B. (2003) The Effective Provision of Pre-School Education [EPPE] Project; Final Report, London: Institute of Education (http://media.education.gov.uk/assets/files/pdf/e/eppe final report 2004.pdf)

Wade, B. \& Moore, M. (2000) 'A Sure Start with books', Early Years, 20 (2), 39-46.

Weitzman, C., Roy, L., Walls, T. \& Tomlin, R. (2004) 'More evidence for Reach Out and Read: A home-based study.' Pediatrics, 113 (5), 1248-1253.

Whitehurst, G., Falco, F., Lonigan, C., Fischel, J., DeBaryshe, B., Valdez-Menchaca, M. \& Caulfield, M. (1988). 'Accelerating language development through picture-book reading'. Developmental Psychology, 24 (4), 522-559. 